\title{
CARDIAC SURGERY WITH CARDIOPULMONARY BYPASS IN PATIENTS WITH CHRONIC RENAL FAILURE
}

İsa Durmaz, MDa

Suat Büket, MD

Yüksel Atay, MDa

Tahir Yağdı, MDa

Mustafa Özbaran, MD

Mehmet Boğa, MDa

Illker Alat, $\mathrm{MD}^{\mathrm{a}}$

Asuman Güzelant, MD $^{\mathrm{b}}$

Şevket Başarır, MDa
Objective: Renal failure is known to increase the morbidity and mortality in patients undergoing cardiac surgery. The results of heart surgery in patients with non-dialysis-dependent, mild renal insufficiency are not clear. Methods: One hundred nineteen adult patients with chronic renal failure underwent cardiac surgery. Group I consisted of 93 patients who had creatinine levels between 1.6 and $2.5 \mathrm{mg} / \mathrm{dL}$ but who were not supported by dialysis. Group II consisted of 18 patients with creatinine levels higher than $2.5 \mathrm{mg} / \mathrm{dL}$ who were not supported by dialysis. Group III consisted of 8 patients with end-stage renal disease who were receiving hemodialysis. Results: The hospital mortality rates were $11.8 \%, 33.0 \%$, and $12.5 \%$, respectively. Morbidity was $21.5 \%, 44.4 \%$, and $\mathbf{7 5 . 0 \%}$, respectively, in groups I, II, and III. Postoperative hemodialysis was needed in $2(2.15 \%)$ patients from group I and $6(33 \%)$ patients from group II. On multivariable logistic regression analysis, risk factors for mortality were preoperative creatinine level more than $2.5 \mathrm{mg} / \mathrm{dL}$, angina class III-IV, emergency operation, excessive mediastinal hemorrhage, postoperative pulmonary insufficiency, low cardiac output, and rhythm disturbances. Risk factors for morbidity were preoperative creatinine level more than $2.5 \mathrm{mg} / \mathrm{dL}$ and postoperative dialysis. Conclusions: Chronic renal failure increases the mortality and morbidity in patients undergoing cardiac surgery. Renal insufficiency with creatinine levels higher than $2.5 \mathrm{mg} / \mathrm{dL}$ increases the risk of postoperative dialysis and prolongs the length of hospital stay. Careful preoperative management and intraoperative techniques, such as avoiding low perfusion pressure and using low-dose dopamine, may be useful for a good operative outcome. (J Thorac Cardiovasc Surg 1999;118:306-15)
C hronic renal failure (CRF) in which glomerular filtration is progressively and irreversibly damaged is an important risk factor for the development of heart diseases. Patients with CRF have an accelerated rate of atherosclerosis, and death rates owing to cardiac disease increase dramatically with age in these patients.

Because of improved diagnostic and therapeutic capabilities, life expectancy was increased in these

From the Ege University Medical Faculty, Department of Cardiovascular Surgery, ${ }^{a}$ and the Konak Mother and Child Health Centre, ${ }^{\mathrm{b}}$ İzmir, Turkey.

Received for publication Nov 5, 1998; revisions requested Jan 28, 1999; final revisions received April 19, 1999; accepted for publication March 2, 1999.

Address for reprints: İsa Durmaz, MD, Ege University Medical Faculty, Department of Cardiovascular Surgery, Bornova, İzmir 35100, Turkey.

Copyright (C) 1999 by Mosby, Inc.

0022-5223/99 $\$ 8.00+0 \quad \mathbf{1 2 / 1 / 9 9 3 6 5}$ patients. In recent years, the number of patients with renal disease who will have coronary artery disease amenable to surgical revascularization is likely to increase. Patients receiving long-term hemodialysis are at a high risk for both mortality and morbidity after cardiac surgery. Performing cardiac surgery in these patients can be challenging. Close teamwork among the cardiac surgeon, anesthesiologist, nephrologist, and cardiologist is essential.

Cardiopulmonary bypass (CPB) has been used with increasing frequency in hemodialysis-dependent patients since a 1968 report by Lansing, Leb, and Berman. ${ }^{1}$ The initial reports were case presentations. ${ }^{2,3}$ Numerous reports have described the results of heart surgery in patients with end-stage CRF. ${ }^{4-10}$ However, few studies have evaluated the results of heart surgery in patients with non-dialysis-dependent, mild renal insufficiency. ${ }^{11-13}$

In this study, we retrospectively reviewed our experi- 
Table I. Patients demographics and preoperative variables (mean $\pm S D$ )

\begin{tabular}{|c|c|c|c|c|c|}
\hline & Total, No. & Group I, No. (\%) & Group II, No. (\%) & Group III, No. (\%) & Statistical significance \\
\hline No. of patients & 119 & $93(78.2)$ & $18(15.1)$ & $8(6.7)$ & \\
\hline \multicolumn{6}{|l|}{ Sex } \\
\hline Male & $108(90.7)$ & 85 (91.4) & $16(88.9)$ & $7(87.5)$ & \\
\hline Female & $11(9.3)$ & $8(8.6)$ & $2(11.1)$ & $1(12.5)$ & \\
\hline Age (y) & $59 \pm 12$ & $60 \pm 12$ & $59 \pm 13$ & $54 \pm 10$ & $\chi^{2}=2.8, P=.2^{*}$ \\
\hline $\operatorname{BSA}\left(\mathrm{m}^{2}\right)$ & $1.78 \pm 0.18$ & $1.77 \pm 0.18$ & $1.80 \pm 0.19$ & $1.75 \pm 0.14$ & $\chi^{2}=1.34, P=.5^{*}$ \\
\hline \multicolumn{6}{|l|}{ Cardiac disease } \\
\hline CAD & $91(76.0)$ & $72(75.8)$ & $12(63.2)$ & $7(87.5)$ & \\
\hline Valvular disease & $21(16.8)$ & $16(16.8)$ & $5(26.3)$ & $0(0.0)$ & \\
\hline Aortic disease & $9(7.2)$ & 7 (7.4) & $2(10.5)$ & $1(12.5)$ & \\
\hline $\operatorname{LVEF}(\%)$ & $46 \pm 11$ & $47 \pm 11$ & $45 \pm 12$ & $48 \pm 11$ & $\chi^{2}=1.16, P=.6^{*}$ \\
\hline \multicolumn{6}{|l|}{ Angina class } \\
\hline I & $11(9.2)$ & $8(8.6)$ & $2(11.1)$ & $1(12.5)$ & \\
\hline II & 73 (61.3) & $59(63.4)$ & $10(55.6)$ & $4(50.0)$ & \\
\hline III & $23(19.3)$ & $17(18.3)$ & $4(22.2)$ & $2(25.0)$ & \\
\hline IV & $12(10.2)$ & $9(9.7)$ & $2(11.1)$ & $1(12.5)$ & \\
\hline
\end{tabular}

$B S A$, Body surface area; $C A D$, coronary artery disease; $L V E F$, left ventricular ejection fraction.

*Kruskal-Wallis test.

Table II. Associated comorbid diseases and risk factors

\begin{tabular}{lcccc}
\hline & Group I, No. (\%) & Group II, No. (\%) & Group III, No. (\%) & Statistical significance \\
\hline DM & $18(19.3)$ & $4(22.2)$ & $2(25.0)$ & $\chi^{2}=0.2, P=.9$ \\
Hypertension & $47(50.5)$ & $8(44.4)$ & $3(37.5)$ & $\chi^{2}=0.38, P=.95$ \\
COPD & $4(4.3)$ & $1(5.6)$ & $0(0.0)$ & $P=.6$ \\
PVD & $11(11.8)$ & $3(16.6)$ & $1(12.5)$ & $\chi^{2}=0.32, P=.8$ \\
AAA & $1(1.1)$ & $0(0.0)$ & $1(12.5)$ & $P=.15$ \\
CVD & $3(3.2)$ & $1(5.6)$ & $0(0.0)$ & $\chi^{2}=0.38, P=.95$ \\
Prior nephrectomy & $2(2.1)$ & $2(11.1)$ & $1(12.5)$ & $\chi^{2}=4.48, P=.11$ \\
Prior MI & $33(35.5)$ & $7(38.9)$ & $1(25.0)$ & $\chi^{2}=0.47, P=.8$ \\
Unstable AP & $9(9.6)$ & $2(11.1)$ & $1(12.5)$ & $\chi^{2}=1.14, P=.6$ \\
Emergency & $6(6.5)$ & $3(16.6)$ & $\chi^{2}=2.23, P=.3$ \\
\hline
\end{tabular}

$D M$, Diabetes mellitus; $C O P D$, chronic obstructive pulmonary disease; $P V D$, peripheral vascular disease; $A A A$, abdominal aortic aneurysm; $C V D$, cerebrovascular disease; $M I$, myocardial infarction; $A P$, angina pectoris.

ence with heart surgery in patients with dialysis-dependent or non-dialysis-dependent renal failure, with particular emphasis on the predictor of mortality and morbidity.

\section{Patients and methods}

From a population of 4855 consecutive patients undergoing heart surgery in the Department of Cardiovascular Surgery at Ege University Medical Faculty between January 1993 and June 1998, 119 patients with preoperative renal failure were identified $(2.45 \%)$. There were $108(90.7 \%)$ male and 11 $(9.2 \%)$ female patients. The mean age was $59 \pm 12$ (range 20 87 years). The patients were divided into 3 groups. Group I consisted of 93 patients with creatinine levels between 1.6 and $2.5 \mathrm{mg} / \mathrm{dL}$, but who were not receiving hemodialysis or peritoneal dialysis. Group II consisted of 18 patients with creatinine levels greater than $2.5 \mathrm{mg} / \mathrm{dL}$ who were not undergoing dialysis. Group III consisted of 8 patients with end-stage renal disease who were receiving hemodialysis (Table I). Informed consent was obtained from all patients.

Ninety-one patients had coronary artery disease (76.5\%). Other cardiac diseases included mitral valve disease in 12 (10.1\%) patients, aortic valve disease in $5(4.3 \%)$, double valve disease in 4 (3.5\%), and thoracic aortic disease in 10 (8.4\%). Hypertension was present in 58 patients. Diabetes mellitus, peripheral vascular disease, and chronic obstructive lung disease were the other additional comorbid diseases. Five patients had prior nephrectomy. Associated comorbid diseases and risk factors are listed in Table II.

Hemodialysis was performed in all patients in group III 16 to 24 hours before the operation. The patients with diseases of the ascending aorta and/or aortic arch were operated on with the aid of deep hypothermic total circulatory arrest. In other patients, CPB was instituted with standard techniques. A membrane oxygenator and roller pump were used in all patients. A bovine heparin dose of approximately $300 \mathrm{IU} / \mathrm{kg}$ 
Table III. Operative variables (mean $\pm S D$ )

\begin{tabular}{|c|c|c|c|c|}
\hline & Group I, No. (\%) & Group II, No. (\%) & Group III, No. (\%) & Statistical significance \\
\hline CABG & $70(75.2)$ & $11(61.0)$ & $7(87.5)$ & \\
\hline $\begin{array}{l}\text { CABG + mitral valve } \\
\text { repair }\end{array}$ & $2(2.1)$ & $1(5.5)$ & $0(0.0)$ & \\
\hline MVR & $7(7.5)$ & $2(11.1)$ & $0(0.0)$ & \\
\hline AVR & $4(4.3)$ & $1(5.5)$ & $0(0.0)$ & \\
\hline $\begin{array}{l}\text { Ascending } \pm \text { arch } \\
\text { operation }\end{array}$ & $7(7.5)$ & $2(11.1)$ & $1(12.5)$ & \\
\hline AVR + MVR & $3(3.2)$ & $1(5.5)$ & $0(0.0)$ & \\
\hline CPB (min) & $96.2 \pm 40.3$ & $109.9 \pm 56.8$ & $87.9 \pm 38.4$ & $\chi^{2}=1.66, P=.4^{*}$ \\
\hline Crossclamp time (min) & $67.8 \pm 30.9$ & $74.3 \pm 31.9$ & $52.4 \pm 7.2$ & $\chi^{2}=3.06, P=.2^{*}$ \\
\hline $\begin{array}{l}\text { Mediastinal drainage } \\
(\mathrm{mL})\end{array}$ & $680.7 \pm 405.5$ & $742.8 \pm 520.6$ & $655.6 \pm 323.1$ & $\chi^{2}=0.21, P=.9^{*}$ \\
\hline $\begin{array}{l}\text { Blood and blood products } \\
\text { (unit) }\end{array}$ & $2.4 \pm 1.4$ & $2.6 \pm 1.8$ & $2.7 \pm 1.7$ & $\chi^{2}=14.5, P=.9^{*}$ \\
\hline
\end{tabular}

$C A B G$, Coronary artery bypass grafting; $M V R$, mitral valve replacement; $A V R$, aortic valve replacement; $C P B$, cardiopulmonary bypass.

*Kruskal-Wallis test.

was given before cannulation. Activated clotting time was maintained higher than 480 seconds during the procedure. Patients were cooled to a rectal temperature of $28^{\circ} \mathrm{C}$, and topical myocardial cooling was accomplished with pericardial lavage with cold saline solution. During CPB the hematocrit level was maintained between 0.20 and 0.25 , pump flow rates between 2.0 and $2.5 \mathrm{~L} \cdot \mathrm{min}^{-1} \cdot \mathrm{m}^{-2}$, and mean arterial pressure about $65 \mathrm{~mm} \mathrm{Hg}$. Blood cardioplegia was used for myocardial protection. The cardioplegic solution was delivered either in an antegrade fashion via the aortic root or coronary ostium or in a retrograde fashion via the coronary sinus. A dopamine infusion $\left(3 \mu \mathrm{g} \cdot \mathrm{kg}^{-1} \cdot \mathrm{min}^{-1}\right)$ was started before CPB to improve renal perfusion in patients in groups I and II. Heparin was reversed by protamine sulfate after decannulation. Ultrafiltration was used in all patients in group III after CPB.

The operative procedures used were coronary artery bypass grafting in 91 patients, mitral valve replacement in 9, aortic valve replacement in 5 , double valve replacement in 4 , the Bentall procedure in 3, replacement of the ascending aorta in 5 , and total arch replacement in 2 (Table III).

Postoperatively, patient management included radial arterial pressure monitoring and use of thermodilution catheters (Swan-Ganz; Baxter Healthcare Corp, Edwards Division, Santa Ana, Calif) to measure cardiac index. Most of the patients received mechanical ventilation overnight and were extubated on the first day after the operation. All patients with dialysis-dependent renal insufficiency underwent postoperative hemodialysis on the second day after the operation.

Perioperative morbidity was defined as one or more of the following: Cardiac complications (myocardial infarction with or without low cardiac output) were defined as conditions that required the use of inotropic agents, intra-aortic balloon pump support, or ventricular assist device support. (The patients who received dopamine or dobutamine, or both, in a dose of more than $5 \mu \mathrm{g} \cdot \mathrm{kg}^{-1} \cdot \mathrm{min}^{-1}$, those who received epinephrine, or those who required intra-aortic balloon pumping were considered to have low cardiac output. This definition was accepted when these therapies were required for longer than 6 hours.) Rhythm disturbances, identified by the need for antiarrhythmic therapies for longer than 6 hours, were also included as postoperative cardiac complications.

Neurologic complications were divided into 2 groups: stroke and temporary neurologic dysfunction. Postoperative stroke was defined as any clinically evident focal or general neurologic deficit that was not present before the operation but was identified after the operation and new lesions diagnosed by computed tomography. Any patients who had not recovered neurologically from the operation within 48 hours and who were comatose or semicomatose were included in the definition of stroke. Temporary neurologic dysfunction was defined as transient disorientation, agitation, delirium, and character changes with no neurologic sequelae.

Respiratory complications were considered to include the necessity for prolonged postoperative mechanical ventilation (>24 hours) or the need for reintubation because of a primary lung failure.

Gastrointestinal complications were defined as the occurrence of gastrointestinal bleeding, mesenteric infarction, or bowel occlusion diagnosed by means of endoscopic evaluation or an abdominal operation.

Postoperative renal failure was defined as urine output of less than $400 \mathrm{~mL}$ in a 24-hour period, a $50 \%$ increase in serum creatinine from baseline, or institution of hemodialysis or peritoneal dialysis. Serious infection was defined as the occurrence of culture-proven pneumonia, mediastinitis, wound infection, urinary tract infection, or septicemia, with appropriate clinical findings.

Death in the intensive care unit within 24 hours after the operation is also included in morbidity because early death precludes observation of morbidity. Operative mortality was defined as any death that occurred during the hospitalization. Any deaths that occurred after discharge from the hospital but 
Table IV. Postoperative variables (mean $\pm S D$ )

\begin{tabular}{|c|c|c|c|c|}
\hline & Group I, No. (\%) & Group II, No. (\%) & Group III, No. (\%) & Statistical significance \\
\hline Mortality & $11(11.8)$ & $6(33.3)$ & $1(12.5)$ & $\chi^{2}=3.06, P=.2$ \\
\hline Cardiac & $6(54.5)$ & $3(50.0)$ & $1(100.0)$ & \\
\hline Renal & $0(0.0)$ & $3(50.0)$ & $0(0.0)$ & \\
\hline Infectious & $2(18.2)$ & $1(16.7)$ & $0(0.0)$ & \\
\hline Pulmonary & $1(9.1)$ & $1(16.7)$ & $0(0.0)$ & \\
\hline Neurologic & $1(9.1)$ & $1(16.7)$ & $0(0.0)$ & \\
\hline GIS & $1(9.1)$ & $0(0.0)$ & $0(0.0)$ & \\
\hline Morbidity & $20(21.5)$ & $8(44.4)$ & $6(75.0)$ & $\chi^{2}=12.947, P=.001$ \\
\hline Cardiac & $14(70.0)$ & $3(37.5)$ & $3(50.0)$ & \\
\hline Pulmonary & $6(30.0)$ & $4(50.0)$ & $1(16.6)$ & \\
\hline Renal & $2(10.0)$ & $6(75.0)$ & $0(0.0)$ & \\
\hline Infectious & $4(20.0)$ & $2(25.0)$ & $0(0.0)$ & \\
\hline Neurologic & $2(10.0)$ & $1(12.5)$ & $0(0.0)$ & \\
\hline GIS & $2(10.0)$ & $0(0.0)$ & $0(0.0)$ & \\
\hline Hemorrhage & $1(5.0)$ & $1(12.5)$ & $0(0.0)$ & \\
\hline Other & $0(0.0)$ & $0(0.0)$ & $2(33.4)$ & \\
\hline In-hospital stay (day) & $20.0 \pm 11.5$ & $26.4 \pm 8.8$ & $13.6 \pm 3.2$ & $\chi^{2}=15.3, P=.0005$ \\
\hline
\end{tabular}

GIS, Gastrointestinal system.

*Kruskal-Wallis test.

within 30 days of the procedure were included as operative mortality unless the cause was clearly unrelated to the operation. The remainder of the deaths were defined as late mortality.

Statistical analysis. The Kruskal-Wallis test and analysis of variance for repeated measures were used for the analysis of continuous data of the 3 groups, and the Wilcoxon matched-pairs signed-rank test was used for each group. The Mann-Whitney $U$ test was used for independent groups. Backward stepwise multivariable logistic regression analysis was used to identify a number of patient-related preoperative, operative, and postoperative predictors of mortality and morbidity. A total of 31 variables were studied: 13 were preoperative (preoperative creatinine level, age, gender, body surface area, presence of hypertension, diabetes mellitus, cerebrovascular disease, peripheral vascular disease, chronic obstructive pulmonary disease, prior myocardial infarction, angina class, family history, and long-term dialysis), 8 were operative (coronary artery bypass surgery, valvular surgery, aortic surgery, CPB time, crossclamp time, emergency status, perioperative excessive mediastinal hemorrhage, and the use of blood or blood products), and 10 were postoperative (postoperative low cardiac output, stroke, transient neurologic deficit, pulmonary insufficiency, acute renal failure necessitating dialysis, gastrointestinal complication, serious infection, rhythm disturbances, multiple system organ failure, and postoperative creatinine level). A contingent probability of .10 or less was used to enter and .15 to remove the variables from the model. Postoperative complications were not taken into account as variables in analyzing postoperative morbidity. The estimated odds ratio was the likelihood of an event in the presence of a variable compared with its likelihood in the absence of that variable. Kaplan-Meier survival analysis was performed for late mortality for the 3 groups, and the mean survival times were given with $95 \%$ confidence intervals. SPSS for Windows release 7.5 (SPSS, Inc, Chicago, Ill) was used for data analysis.

\section{Results}

Eighteen patients died in the hospital, for an overall 30-day mortality rate of $15.1 \%$. The causes of death were cardiac in 10 patients, renal in 3 , infectious in 3 , cerebrovascular in 2, pulmonary in 2 , and gastrointestinal in 2. The hospital mortality rates for patients in groups I, II, and III were 11 (11.8\%), 6 (33.3\%), and 1 (12.5\%), respectively (Table IV). On multivariable analysis, perioperative variables significantly associated with increased risk for in-hospital mortality were preoperative creatinine level greater than $2.5 \mathrm{mg} / \mathrm{dL}$, angina class III-IV, excessive mediastinal hemorrhage, emergency status, postoperative pulmonary insufficiency, low cardiac output, and rhythm disturbances (Table V).

Fifty-four postoperative complications were observed in 34 patients, for an early morbidity rate of $28.6 \%$. Complications were cardiac in 20 patients, pulmonary in 11 , infectious in 6 , renal in 8 , neurologic in 3 , and gastrointestinal in 2. Cardiac complications included arrhythmias in 12 patients and low cardiac output in 8. Pulmonary complications included respiratory failure in 6 patients ( 2 of them required a tracheostomy), pleural effusion necessitating tube thoracostomy drainage in 4 , and aspiration pneumonia in 1 patient. There were 2 minor leg wound infections, 2 sternal wound infections, 1 urinary tract infection, and 1 case of sepsis syndrome. Neurologic complications 
Table V. The predictors of early mortality, morbidity, and postoperative renal failure

\begin{tabular}{|c|c|c|c|}
\hline & Predictive factors & $P$ value & Odds ratio $*(95 \%$ CI $)$ \\
\hline \multicolumn{4}{|l|}{ Early mortality } \\
\hline \multirow[t]{2}{*}{ Preoperative } & Creatinine $>2.5 \mathrm{mg} / \mathrm{dL}$ & .02 & $4.58(1.26-16.72)$ \\
\hline & Angina class III-IV & .02 & $5.96(1.94-18.27)$ \\
\hline \multirow{2}{*}{ Perioperative } & Excessive hemorrhage & .04 & $3.98(1.05-15.09)$ \\
\hline & Emergency & .02 & $6.45(1.38-30.08)$ \\
\hline \multirow[t]{4}{*}{ Postoperative } & Pulmonary insufficiency & .002 & $57.75(11.73-929.91)$ \\
\hline & Low cardiac output & .0001 & $257.0(13.38-2733.02)$ \\
\hline & Infection & .06 & $20.73(2.21-229.07)$ \\
\hline & Rhythm disturbances & .01 & $28.05(2.26-298.09)$ \\
\hline \multicolumn{4}{|l|}{ Early morbidity } \\
\hline Preoperative & Creatinine $>2.5 \mathrm{mg} / \mathrm{dL}$ & .003 & $4.24(1.61-11.11)$ \\
\hline Perioperative & $\mathrm{CPB}>90$ minutes & .06 & $8.81(1.18-89.27)$ \\
\hline Postoperative & Dialysis & .0002 & $9.20(4.13-15.38)$ \\
\hline \multicolumn{4}{|c|}{ Postoperative acute renal failure } \\
\hline Preoperative & Creatinine $>2.5 \mathrm{mg} / \mathrm{dL}$ & .01 & $22.93(1.90-276.00)$ \\
\hline \multirow[t]{3}{*}{ Postoperative } & Infection & .0001 & $356.03(17.38-7292.01)$ \\
\hline & Low cardiac output & .02 & $23.83(1.79-316.01)$ \\
\hline & Pulmonary insufficiency & .02 & $20.64(1.62-262.75)$ \\
\hline
\end{tabular}

$C P B$, Cardiopulmonary bypass.

*Multivariable.

Table VI. Differences in creatinine levels

\begin{tabular}{|c|c|c|c|c|c|c|}
\hline \multirow[b]{2}{*}{ Group } & \multirow[b]{2}{*}{ No. } & \multicolumn{2}{|c|}{ Preoperative } & \multicolumn{3}{|c|}{ Postoperative } \\
\hline & & $\begin{array}{c}\text { Mean } \pm S D \\
(\text { min-max })\end{array}$ & $\begin{array}{c}95 \% \text { CI } \\
\text { for the mean }\end{array}$ & $\begin{array}{c}\text { Mean } \pm S D \\
\text { (min-max) }\end{array}$ & $\begin{array}{l}95 \% \text { CI } \\
\text { for the mean }\end{array}$ & $\begin{array}{c}\text { Statistical } \\
\text { significance }^{*}\end{array}$ \\
\hline Group I & 93 & $\begin{array}{l}1.8 \pm 0.2 \\
(1.5-2.4)\end{array}$ & $1.8-1.9$ & $\begin{array}{l}1.9 \pm 0.5 \\
(1.0-4.0)\end{array}$ & $1.8-2.0$ & $\begin{array}{l}\mathrm{Z}=-1.1648 \\
P=.2\end{array}$ \\
\hline Group II & 18 & $\begin{array}{l}3.3 \pm 1.0 \\
(2.5-6.1)\end{array}$ & $2.8-3.8$ & $\begin{array}{l}4.0 \pm 1.0 \\
(2.7-5.6)\end{array}$ & $3.5-4.5$ & $\begin{aligned} \mathrm{Z} & =2.2211 \\
P & =.03\end{aligned}$ \\
\hline Group III & 8 & $\begin{array}{l}7.6 \pm 2.4 \\
(5.2-11.3)\end{array}$ & $5.6-9.7$ & $\begin{array}{l}6.7 \pm 2.7 \\
(3.7-11.6)\end{array}$ & $4.4-9.0$ & $\begin{array}{l}Z=-1.4201 \\
P=.7\end{array}$ \\
\hline Total & 119 & $\begin{array}{l}2.4 \pm 1.7 \\
(1.5-11.3)\end{array}$ & $2.1-2.7$ & $\begin{array}{l}2.6 \pm 1.6 \\
(1.0-11.6)\end{array}$ & $2.3-2.9$ & $\begin{array}{l}\mathrm{Z}=-1.754 \\
P=.08\end{array}$ \\
\hline
\end{tabular}

*Wilcoxon matched-pairs signed-rank test.

included strokes in 2 patients and intracerebral hemorrhage in 1 patient. Gastrointestinal complications included bleeding and acute cholecystitis in 1 patient each. Two patients required reoperation for excessive mediastinal hemorrhage. The complication directly related to hemodialysis in our patients was thrombotic occlusion of a fistula in 2 patients. The hospital morbidity for patients in groups I, II, and III were 20 (21.5\%), 8 (44.4\%), and 6 (75.0\%), respectively (Table IV). On multivariable analysis with the use of logistic regression, perioperative variables significantly associated with increased risk for in-hospital morbidity were preoperative creatinine level greater than $2.5 \mathrm{mg} / \mathrm{dL}$ and postoperative dialysis (Table V).

The average postoperative drainage for 24 hours was
$688.4 \pm 31.3 \mathrm{~mL}$. Only 2 patients returned to the operating room for bleeding. Sites of bleeding were discovered in both patients, so that coagulopathy related to renal failure was not considered to be the cause. Total blood product administration during the operation or within 24 hours after the operation averaged $2.46 \pm 1.5$ U. In group III, we used an autotransfusion device to concentrate suctioned mediastinal blood during the operation. The amounts of postoperative blood loss and transfusion requirements of the 3 groups were compared. Although the difference was not statistically significant (Kruskal-Wallis $\chi^{2}$ test $=14.5, P=.93$ ), the number of units of red cells transfused was slightly higher in group III than in the other groups (Table III). The greater number of units of blood transfused in this 


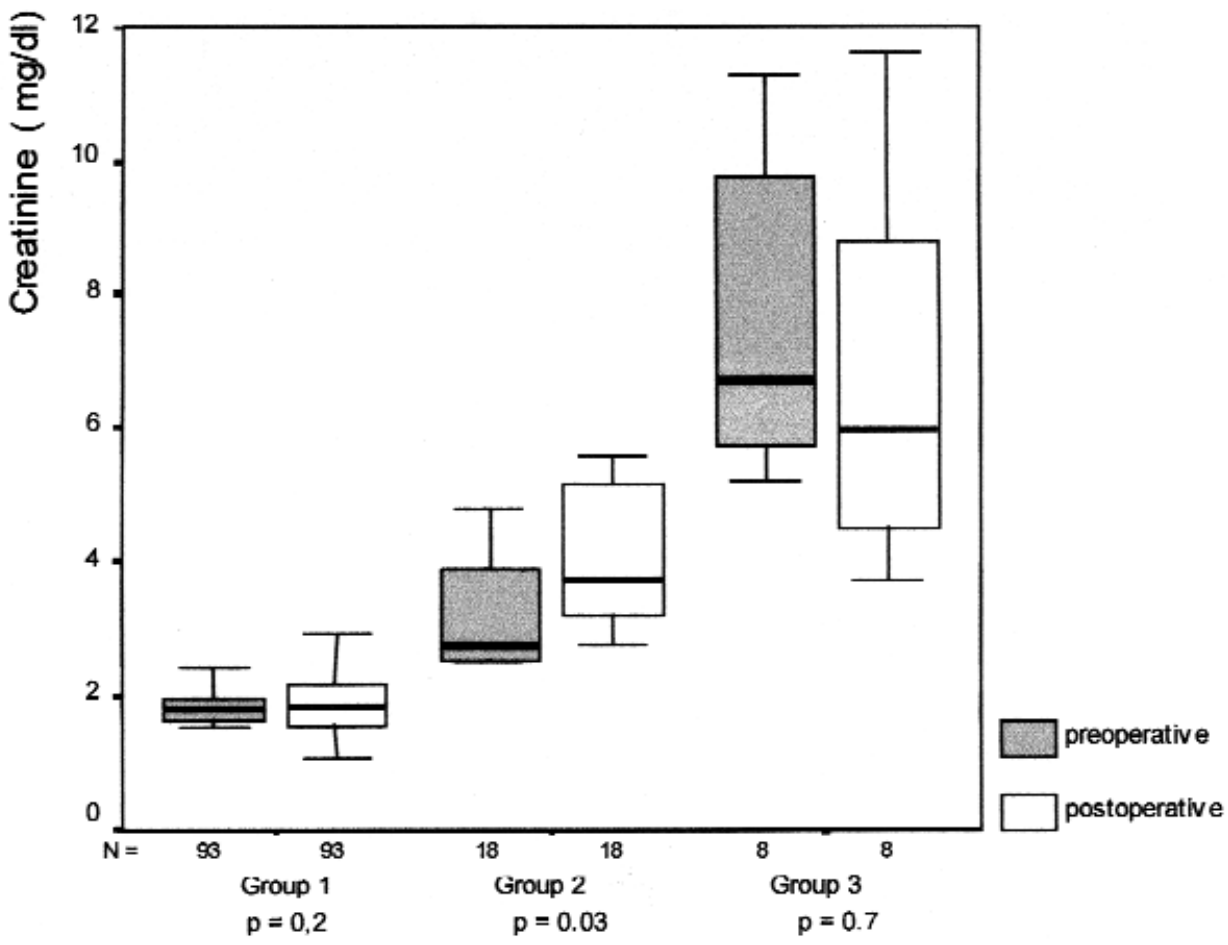

Fig 1. Changes in serum creatinine after CPB. In patients in group II, differences between preoperative and postoperative levels were statistically significant (Wilcoxon test).

Table VII. Morbidity and mortality of cardiac surgery in the different series of patients having dialysis

\begin{tabular}{|c|c|c|c|c|c|c|}
\hline \multirow[b]{2}{*}{ First author } & \multirow[b]{2}{*}{ Year } & \multirow[b]{2}{*}{ No. of patients } & \multicolumn{2}{|c|}{ Morbidity } & \multicolumn{2}{|c|}{ Mortality } \\
\hline & & & No. & $\%$ & No. & $\%$ \\
\hline Marshall $^{16}$ & 1986 & 12 & 2 & 16.7 & 1 & 8.3 \\
\hline Laws $^{7}$ & 1986 & 10 & 6 & 60.0 & 1 & 10.0 \\
\hline Blakeman $^{17}$ & 1989 & 21 & 15 & 71.4 & 2 & 9.5 \\
\hline $\mathrm{Ko}^{18}$ & 1993 & 25 & 18 & 72.0 & 4 & 16.0 \\
\hline Kaul $^{19}$ & 1994 & 35 & 23 & 65.7 & 4 & 11.4 \\
\hline Owen $^{20}$ & 1994 & 21 & 10 & 47.6 & 2 & 9.5 \\
\hline Samuels ${ }^{11}$ & 1996 & 13 & 10 & 76.9 & 4 & 30.8 \\
\hline Present study & & 8 & 6 & 75.0 & 1 & 12.5 \\
\hline
\end{tabular}

group was not due to greater postoperative blood loss. There were no significant differences between the groups in terms of CPB time, crossclamp time, and the amount of postoperative blood loss (Table III).

An analysis of the mean creatinine values in group I patients on admission and in the postoperative period showed a minimal and nonsignificant increase from 1.8 $\pm 0.2 \mathrm{mg} / \mathrm{dL}$ to $1.9 \pm 0.5 \mathrm{mg} / \mathrm{dL}$. Only 2 patients in this group required postoperative dialysis $(2.2 \%)$. In group II the mean preoperative creatinine value was $3.3 \pm 1.0$ $\mathrm{mg} / \mathrm{dL}$. After the operation this value increased significantly to $4.0 \pm 1.0 \mathrm{mg} / \mathrm{dL}$ (Table VI). Six patients in group II required postoperative dialysis (33.3\%). In groups I and II, multivariable analysis was used for identifying perioperative risk factors for postoperative acute renal failure necessitating dialysis. Preoperative creatinine level greater than $2.5 \mathrm{mg} / \mathrm{dL}$, postoperative pulmonary insufficiency, low cardiac output, and serious infection were found to be independent predictors (Table V). In group III, postoperative mean creatinine value was found to be slightly lower than the preoperative value $(7.6 \pm 2.4$ vs $6.7 \pm 2.7 \mathrm{mg} / \mathrm{dL})($ Fig 1$)$.

For the 101 patients who were discharged from the hospital, the average length of stay in the hospital for 


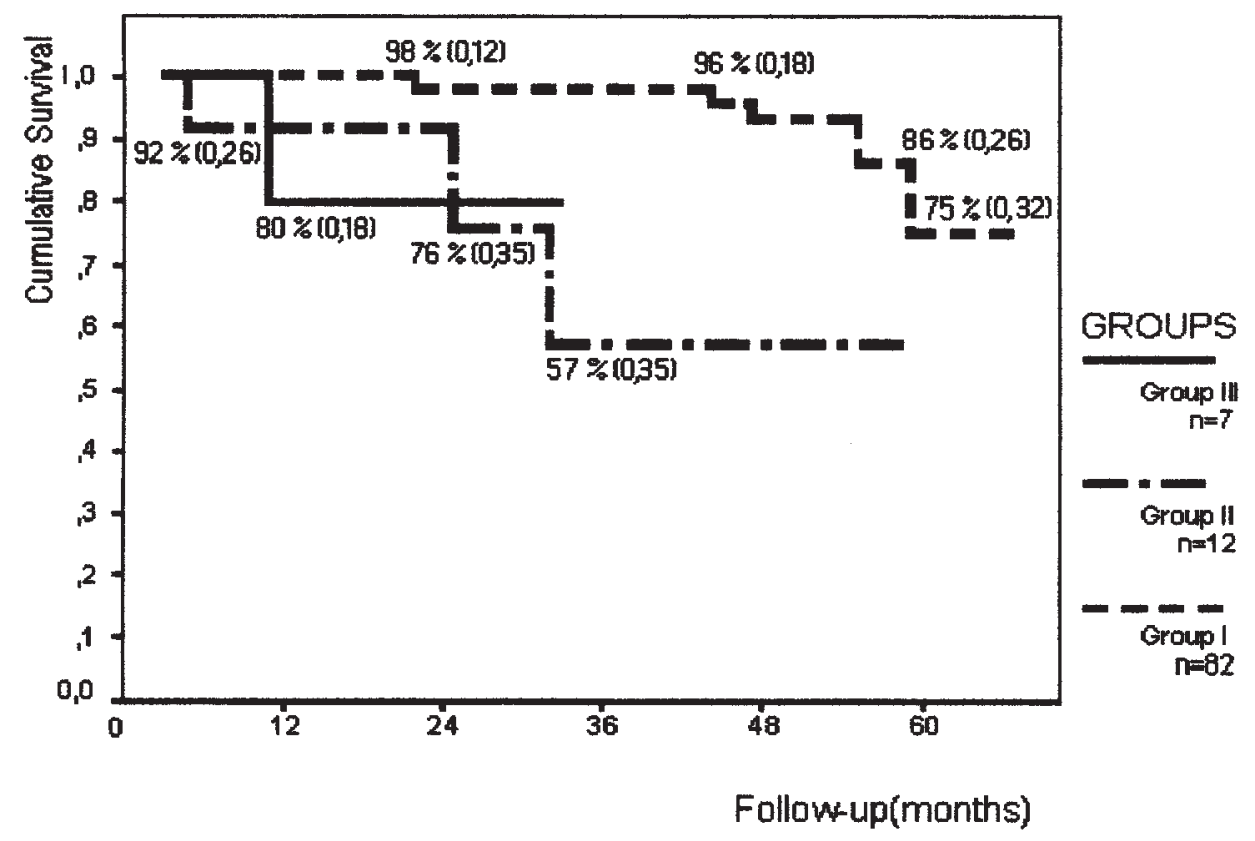

Fig 2. Comparison of survival curves in patients with different stages of renal failure (standard deviations are given in parentheses).

Table VIII. Morbidity and mortality of patients with non-dialysis-dependent renal insufficiency

\begin{tabular}{|c|c|c|c|c|c|c|c|}
\hline \multirow[b]{2}{*}{ First author } & \multirow[b]{2}{*}{ Year } & \multirow{2}{*}{$\begin{array}{c}\text { Creatinine level } \\
(\mathrm{mg} / \mathrm{dL})\end{array}$} & \multirow[b]{2}{*}{ No. of patients } & \multicolumn{2}{|c|}{ Morbidity } & \multicolumn{2}{|c|}{ Mortality } \\
\hline & & & & No. & $\%$ & No. & $\%$ \\
\hline Zanardo $^{23}$ & 1994 & $>1.5$ & 41 & 13 & $31.7^{*}$ & 7 & 17.1 \\
\hline Samuels ${ }^{11}$ & 1996 & $\geq 1.6$ & 31 & 25 & $80.6 \dagger$ & 6 & 19.3 \\
\hline $\operatorname{Rao}^{12}$ & 1997 & $>1.7$ & 38 & 19 & 50.0 \% & 2 & 5.3 \\
\hline Present study & & $>1.6$ & 111 & 28 & $25.2 \dagger$ & 17 & 15.3 \\
\hline
\end{tabular}

*Only cardiac morbidity.

$\dagger$ Total morbidity.

\$Cardiac and renal morbidity.

patients in groups I, II, and III were $20.02 \pm 11.46$ days (6-71 days), $26.42 \pm 8.77$ days (15-45 days), and 13.57 \pm 3.15 days (10-19 days), respectively (Kruskal Wallis test $\left.\chi^{2}=15.3, P=.0005\right)$.

There was no significant differences between the average length of hospital stay of group I and group III patients $(U=175, P=.089)$. Follow-up was complete in all hospital survivors $(\mathrm{n}=101)$, with a mean followup of $34.8 \pm 16.4$ months (3-67 months). Follow-up information was obtained on all patients by direct telephone contact or clinical examination. There were 9 late deaths $(8.9 \%)$. The causes of death were cardiac in 4 patients, renal in 2, pulmonary in 1 , and unknown in 2 patients. The late mortality rates for patients in groups I, II, and III were $6.1 \%, 25 \%$, and $14.3 \%$, respectively. The mean survival times are different for each of the 3 groups. Although the long-term survival is reduced in group II patients, it is difficult to interpret the results because of the small sample sizes of the second and the third groups and the number of deaths in the groups (Fig 2).

\section{Conclusion}

Cardiac disease continues to be a major cause of death in patients with CRF and is responsible for up to $60 \%$ of all causes of death. ${ }^{14,15}$ It has been stated that atherosclerosis is accelerated in patients undergoing long-term hemodialysis. Hyperlipidemia, hypertension, renal ane- 
mia, increased volume load caused by arteriovenous shunts, platelet dysfunction, and abnormalities in the metabolism of calcium and triglycerides are main factors that increase the incidence of cardiac diseases. Patients requiring long-term hemodialysis are known to be at a high risk for both mortality and morbidity during heart surgery. In the literature, morbidity in different series ranged from $17 \%$ to $77 \%$. In most of these series, morbidity was $60 \%$ or higher. Mortality in these series ranged from $8 \%$ to $31 \% .^{7,11,16-20}$ Our morbidity and mortality were $75.0 \%$ and $12.5 \%$, respectively (Table VII). Despite this increased risk, long-term studies have demonstrated a benefit of surgical revascularization over percutaneous transluminal coronary angioplasty in both overall survival and angina-free survival. ${ }^{21}$ Kahn and associates ${ }^{22}$ found that the restenosis rate is higher in patients undergoing dialysis than in the routine population undergoing coronary angioplasty.

End-stage renal failure has been viewed as an important preoperative predictor of surgical outcome; however, the impact of renal impairment on the results of heart surgery has been somewhat ill defined. Ideally, creatinine clearance should be used to assess risk, because serum creatinine levels are dependent on body size and state of hydration. However, serum creatinine levels can be used as an adequate indicator of renal function. Thus mild elevation of serum creatinine may reflect a significant impairment of renal function. For practical purposes, we used the serum creatinine levels taken from the patients. There is considerably less information in the literature about operative morbidity and mortality in patients with CRF who are not undergoing dialysis. A limited number of series show that morbidity ranged from $32 \%$ to $80 \%$ and mortality ranged from $5 \%$ to $19 \%{ }^{11,12,23}$ Our morbidity and mortality were $25.2 \%$ and $15.3 \%$, respectively, in patients with non-dialysisdependent renal insufficiency (Table VIII).

In patients with CRF the preoperative, intraoperative, and postoperative care are important. In our practice, all patients with dialysis-dependent renal insufficiency underwent preoperative hemodialysis within 24 hours of the operation, the second day after the operation, and then according to their preoperative routine or as dictated by the nephrologist. We prefer peritoneal dialysis if the hemodynamics of the patient is unstable. None of the patients in group III required postoperative peritoneal dialysis.

The serum potassium level was corrected to the range of 3.5 to $5.0 \mathrm{mmol} / \mathrm{L}$. The patients were given blood transfusions before the operation if the hematocrit value was lower than $25 \%$. Cephalosporins were given for antibiotic prophylaxis. The patients were taken to the operating room with optimal hydration and electrolyte balance. Myocardial depressants were avoided, and minimal intravenous fluids, consisting of 5\% dextrose in water, were administered. The use of intraoperative hemodialysis was advocated by some groups. ${ }^{24,25}$ Intraoperative ultrafiltration is valuable in removing excess plasma water during $\mathrm{CPB}$. It also avoids the hemodynamic instability and the risk of heparin-associated bleeding associated with the use of hemodialysis. We used continuous hemodiafiltration during and after CPB in all dialysis-dependent patients, and we did not see any complication related to this procedure. The chronic anemia and platelet function disturbances may obligate them to a greater requirement for transfusion of blood products in the perioperative period. In dialysis-dependent patients we used an autotransfusion device to concentrate suctioned mediastinal blood during the operation. In our study, the blood product requirements of dialysis-dependent patients with renal failure were slightly greater than those of non-dialysis-dependent patients. The greater number of units of red cells used possibly reflected more intraoperative usage, which was due to lower preoperative hematocrit levels in these patients. The chronic arteriovenous fistulas of patients with end-stage CRF are at risk for thrombosis during the operation, probably from low peripheral perfusion during CPB or applied pressure to the fistula during arm positioning. In group III, 2 of 8 patients had this complication. In both of these patients, hemodialysis was performed with a temporary hemodialysis catheter inserted through the subclavian vein. Revisions of fistulas were made before discharge. Inasmuch as dialysis access sites are finite, the arteriovenous fistulas should be protected carefully by proper positioning.

Regular estimation of the acid-base balance and electrolyte concentrations is essential during the postoperative period for detecting and treating abnormalities. Assessment of tissue perfusion and measurements of daily weights, blood pressure, pulse rate, and central venous pressure are mandatory for correct management. The most important electrolyte imbalance in CPB operations is that of potassium, because elevated and reduced levels are associated with life-threatening arrhythmia, especially after ischemia. In our study, ventricular arrhythmia and fibrillation were common causes of morbidity in dialysis-dependent patients and were responsible for 50\% (3 patients) of all causes of morbidity. Fluid restriction is essential in patients with long-term hemodialysis. In non-dialysis-dependent patients, volume replacement must be according to urine output. In these patients, excessive fluid restric- 
tion may cause acute renal failure. We applied routine administration of dopamine hydrochloride in patients with serum creatinine levels of more than $1.6 \mathrm{mg} / \mathrm{dL}$ and took aggressive measures to assure adequate hydration and to maintain urine output during the operation. Postoperative early hemodialysis may be useful in patients with inadequate urine output and a high potassium level. In patients in group I or II, we used some criteria for initiating dialysis. Dialysis was instituted whenever a $50 \%$ increase in serum creatinine from baseline was observed or the patient exhibited inadequate urine output ( $<400 \mathrm{~mL}$ for 24 hours) despite correction of hemodynamic status and diuretic therapy, especially if fluid overload, hyperkalemia, or metabolic acidosis was also present. If hemodynamic status was not stable, peritoneal dialysis was commenced (4/111 patients in groups I and II).

The use of peritoneal dialysis has some advantages over hemodialysis in the early postoperative period. Peritoneal dialysis can be initiated with minimal equipment and does not require specialized personnel. It also avoids the potential complications of abrupt hemodynamic changes or the risk of heparin-associated bleeding that may occur with the use of hemodialysis. Peritoneal dialysis allows a prolonged delay in the reinstitution of hemodialysis. Especially in group II patients, early institution of peritoneal dialysis may be of great benefit. However, peritoneal dialysis may be contraindicated when there is continuity of the thorax or pericardium (or both) with the abdominal cavity. Risks of peritonitis, respiratory disturbances, and protein loss are other drawbacks of the peritoneal dialysis.

In patients with moderate elevation of serum creatinine levels $(1.6 \mathrm{mg} / \mathrm{dL}$ through $2.5 \mathrm{mg} / \mathrm{dL})$, there is less probability of postoperative dialysis, but preoperative values of greater than $2.5 \mathrm{mg} / \mathrm{dL}$ are associated with a markedly increased risk. Accordingly, in group I, 2 of 93 patients needed postoperative dialysis (2.2\%), whereas 6 patients in group II progressed to dialysis during the hospital course $(33 \%)(P=.003)$. Hemodialysis was performed in 4 of them. The remaining 4 patients were entered into the peritoneal dialysis program because of hemodynamic instability. It is clear that the status of patients with CFR worsened after $\mathrm{CPB}$, particularly in those with creatinine values higher than $2.5 \mathrm{mg} / \mathrm{dL}$. CPB in patients with CRF poses a special problem because of the excessive fluid shifts in the different body compartments during CPB. With reduced renal capacity, the tolerance to CPB is worsened. The outcome of the operation depends in part on the ability of the kidneys to deal with those fluid shifts. Group II patients seem more susceptible to the adverse effect of CPB because they have more advanced compromise of renal function than the group I patients.

At present, the overall mortality of cardiac surgery with CPB is $3.5 \%$ at our clinic. This represents less than one fourth of the mortality in patients with CRF $(15.1 \%)$. The incidence of mortality was also considerably higher in patients with preoperative creatinine levels greater than $2.5 \mathrm{mg} / \mathrm{dL}$ (33\%). Especially in groups II and III, the postoperative course was complicated in most cases. In patients with non-dialysis-dependent renal failure, when postoperative renal failure is severe enough to require dialysis, morbidity and mortality are markedly increased despite dialysis and intensive supportive care. In addition to problems in the management of fluid and electrolytes, a number of comorbid factors such as low cardiac output state, bleeding diathesis, and susceptibility to infection predispose these patients to increased operative morbidity and mortality. In 6 patients in group II, the postoperative period was complicated by acute renal failure necessitating dialysis, and 4 of the patients died. In patients with preoperative renal failure with long-term hemodialysis, when dialysis is performed the day before and then the normal dialysis routine is resumed on the second postoperative day, the renal management of these patients is straightforward. In group III, all patients were in hemodynamically stable condition in the early postoperative period and none of them needed inotropic agents or peritoneal dialysis immediately after the operation. In group III patients CPB procedures were performed with a good operative outcome. Because major morbidity that necessitates longer hospitalization was more common in group II patients, the average hospitalization time was significantly longer when compared with that of group III patients. Group III patients are under the care of a nephrologist for a long time and no additional preoperative evaluation is needed in these patients, but preoperative diagnostic facilities and consultations cause longer preoperative stays in group II patients.

In conclusion, the patients with CRF with significant comorbid diseases should be evaluated carefully. Preoperative renal failure increases the mortality and morbidity in patients undergoing heart surgery. Our results suggest that even those patients with relatively mild renal insufficiency remain at risk for a poor outcome. In patients with creatinine levels higher than 2.5 $\mathrm{mg} / \mathrm{dL}$, there is a strong likelihood of postoperative dialysis besides increased risks of mortality and morbidity. It is important to develop methods of identifying patients at high risk for perioperative renal failure because renal ischemia is generally silent, unlike 
ischemia of the coronary, cerebral, and peripheral vascular beds, which are usually overt, manifested by angina pectoris, neurologic sequelae, and claudication, respectively. Reduced baseline renal function can be used to stratify patients before surgery and to identify several subgroups of patients at substantially increased risk. A prospective randomized trial is required to assess the long-term results of heart surgery in patients with different stages of renal failure. In group II patients, correct evaluation of the necessity of dialysis and proper timing to start it will be a major concern of future studies.

\section{REFERENCES}

1. Lansing AM, Leb DE, Berman LB. Cardiovascular surgery in end-stage renal failure. JAMA 1968;204:134-8.

2. Ribot S, Gilbert L, Rothfeld EL, Parsonnet V, Jacobs MG. Bacterial endocarditis with pulmonary edema necessitating mitral valve replacement in a hemodialysis-dependent patient. J Thorac Cardiovasc Surg 1971;62:59-62.

3. Menzoian J, Davis RC, Idelson BA, Mannick JA, Berger RL. Coronary artery bypass surgery and renal transplantation: a case report. Ann Surg 1974;179:63-4

4. Lamberti JJ, Cohn LH, Collins JJ. Cardiac surgery in patients undergoing renal dialysis or transplantation. Ann Thorac Surg 1975;19:135-41.

5. Crawford FA Jr, Selby JH Jr, Bower JD, Lehan PH. Coronary revascularization in patients maintained on chronic hemodialysis. Circulation 1977;56:684-7.

6. Siegel MS, Norfleet EA, Gitelman HJ. Coronary artery bypass surgery in a patient receiving hemodialysis. Arch Intern Med 1977;137:83-4

7. Laws KH, Merrill WH, Hammon JW, Prager LR, Bender HW. Cardiac surgery in patients with chronic renal disease. Ann Thorac Surg 1986;42:152-7.

8. Love JW, Jahnke EJ, McFadden RB, Murray JJ, Latimer RG, Gebhart WF, et al. Myocardial revascularization in patients with chronic renal failure. J Thorac Cardiovasc Surg 1980;79:625-7.

9. Manhas DR, Merendino KA. The management of cardiac surgery in patients with chronic renal failure. J Thorac Cardiovasc Surg 1972;63:235-9

10. McGovern E, Rooney R, Neligan MC. Open heart surgery in patients receiving chronic haemodialysis. Thorax 1984;39:388-9.

11. Samuels LE, Sharma S, Morris RJ, Kuretu R, Grunewald KE,
Strong MD, et al. Coronary artery bypass grafting in patients with chronic renal failure: a reappraisal. J Card Surg 1996;11: 128-33.

12. Rao V, Weisel RD, Buth KJ, Cohen G, Borger MA, Shiono N, et al. Coronary artery bypass grafting in patients with non-dialysisdependent renal insufficiency. Circulation 1997;96(Suppl):II 1138-45.

13. Higgins TL, Estafanous FG, Loop FD, Blum JM, Paranandi L. Stratification of morbidity and mortality outcome by preoperative risk factors in coronary artery bypass patients. JAMA 1992; 267:2344-8.

14. US Renal Data System. USRDS 1991 Annual Data Report. Bethesda (MD). Natl Inst Diabetes Dig Kidney Dis 1991;31-40.

15. Burton BT, Krueger KK, Bryan FA. National registry of longterm dialysis patients. JAMA 1971;218:718.

16. Marshall WG, Rossi NP, Meng RL, Wedige-Stecher T. Coronary artery bypass grafting in dialysis patients. Ann Thorac Surg 1986;42:S12-5

17. Blakeman BM, Pifarré R, Sullivan HJ, Montoya A, Bakhos M. Cardiac surgery for chronic renal dialysis patients. Chest 1989; 95:509-11.

18. Ko W, Kreiger KH, Isom OW. Cardiopulmonary bypass procedures in dialysis patients. Ann Thorac Surg 1993;55:677-84.

19. Kaul TK, Fields BL, Reddy MA, Kahn DR Cardiac operations in patients with end stage renal disease. Ann Thorac Surg 1994; 57:691-6.

20. Owen CH, Cummings RG, Sell TL, Schwab SJ, Jones RH, Glower DD. Coronary artery bypass grafting in patients with dialysis-dependent renal failure. Ann Thorac Surg 1994;58:1729-33.

21. Koyanagi T, Nishida H, Kitamura M, Endo M, Koyanagi H, Kawaguchi M, et al. Comparison of clinical outcomes of coronary artery bypass grafting and percutaneous transluminal coronary angioplasty in dialysis patients. Ann Thorac Surg 1996;61: 1793-6.

22. Kahn JK, Rutherford BD, McConahay DR, Johnson WL, Giorgi LV, Hartzler GO. Short- and long-term outcome of percutaneous transluminal coronary angioplasty in chronic dialysis patients. Am Heart J 1990;119:484-9.

23. Zanardo G, Michielon P, Paccagnella A, Rosi P, Calo M, Salandin $\mathrm{V}$, et al. Acute renal failure in the patient undergoing cardiac operation: prevalence, mortality rate, and main risk factors. $\mathrm{J}$ Thorac Cardiovasc Surg 1994;107:1489-95.

24. Sutton RG. Renal considerations, dialysis, and ultrafiltration during CPB. Int Anesthesiol Clin 1996;34:165-76.

25. Kubota T, Miyata A, Maeda A, Hirota K, Koizumi S, Ohba H. Continuous haemodiafiltration during and after $\mathrm{CPB}$ in renal failure patients. Can J Anaesth 1997;44:1182-6. 